REVISTA

\title{
EFEITO DA APLICAÇÃO DE ÁCIDO-INDOL-3-BUTÍRICO NO CRESCIMENTO E QUALIDADE DE MUDAS DE Piper nigrum L. CV. KOTTANADAN PROPAGADAS VEGETATIVAMENTE
}

\author{
EFFECT OF INDOL-3-BUTYRIC ACID APPLICATION ON GROWTH AND \\ QUALITY OF Piper nigrum L. SEEDLINGS CV. KOTTANADAN \\ VEGETATIVELY PROPAGATED
}

\author{
Vinicius de Souza Oliveira ${ }^{1 *}$ \\ Pietra de Souza Rodrigues ${ }^{2}$ \\ Stanley Bravo Buffon ${ }^{3}$ \\ Andréia Lopes de Morais ${ }^{4}$ \\ Sara Dousseau Arantes 5 \\ Jasmyn Tognere ${ }^{6}$ \\ Pablo Santana $\mathrm{Vial}^{7}$ \\ Omar Schmildt ${ }^{8}$ \\ Edilson Romais Schmildt ${ }^{9}$
}

\begin{abstract}
${ }^{1}$ Universidade Federal do Espírito Santo, CCAE, ES, Brasil; souzaoliveiravini@gmail.com.
${ }^{2}$ Universidade Federal do Espírito Santo, CEUNES, ES, Brasil; pietra_sr@hotmail.com.

${ }^{3}$ Universidade Federal do Espírito Santo, CEUNES, ES, Brasil; stanleybbuffon@ gmail.com. ${ }^{4}$ Universidade Federal do Espírito Santo, CEUNES, ES, Brasil; andreia-lopes02@ hotmail.com. ${ }^{5}$ Instituto Capixaba de Pesquisa, Assistência Técnica e Extensão Rural (INCAPER), Linhares,

ES, Brasil. E-mail: saradousseau @gmail.com.

${ }^{6}$ Universidade Federal do Espírito Santo, CEUNES, ES, Brasil; tognerejasmyn@ gmail.com.

${ }^{7}$ Universidade Federal do Espírito Santo, CEUNES, ES, Brasil; pabblo22@live.com.

${ }^{8}$ Universidade Federal do Espírito Santo, CEUNES, ES, Brasil; omarschmildt@ gmail.com.

${ }^{9}$ Universidade Federal do Espírito Santo, CEUNES, ES, Brasil; e.romais.s@ gmail.com.
\end{abstract}

*Autor de correspondência

Artigo submetido em 15/12/2019, aceito em 19/02/2020 e publicado em 28/08/2020

Resumo: A pimenteira-do-reino (Piper nigrum L.) é amplamente utilizada para diversos fins, tais como, plantas ornamentais, condimentos e até empregada na medicina popular. Desta forma, o objetivo do estudo foi verificar o efeito da aplicação de diferentes doses de ácido-indol-3-butírico (AIB) no crescimento e na qualidade de mudas da cultivar Kottanadan. $\mathrm{O}$ estudo foi realizado no viveiro da fazenda Experimental do Instituto Capixaba de Pesquisa, Assistência Técnica e Extensão Rural, situado no Norte do Estado do Espírito Santo, Brasil. Foram utilizadas estacas da cultivar Kottanadan, com aplicação de AIB via líquido, nas dosagens de: 0, 500, 1000, 1500 e $2000 \mathrm{mg} \mathrm{L}^{-1}$. As mudas foram dispostas em delineamento de blocos casualizados, com quatro repetições, sendo cada unidade experimental constituída por 25 plantas, totalizando 500 plantas no campo experimental. Aos 
185 dias após o plantio foram avaliadas as características: altura de planta; comprimento do sistema radicular; área foliar; diâmetro do caule; massa seca da parte área; massa seca do sistema radicular; massa seca total; e estimado índice de qualidade de Dickson. A aplicação de AIB promoveu melhoras no crescimento e na qualidade de mudas, entretanto as concentrações elevadas limitaram seu desenvolvimento. Assim, indicamos a concentração de $1420,10 \mathrm{mg} \mathrm{L}^{-1}$, pois esta dosagem implicou em melhor qualidade das mudas.

Palavras-chave: Pimenteira-do-reino; regulados de crescimento, auxina exógena.

\begin{abstract}
The black pepper (Piper nigrum L.) is widely used for various purposes, such as ornamental plants, condiments and even employed in folk medicine. Thus, the objective of the study was to verify the effect of the application of different doses of indole-3-butyric acid (IBA) on the growth and quality of seedlings of cultivar Kottanadan. The study was carried out at the Experimental farm nursery of the Capixaba Institute for Research, Technical Assistance and Rural Extension, located in the north of Espírito Santo State, Brazil. Cuttings of cultivar Kottanadan were used, with application of IBA via liquid at the dosages of: $0,500,1000,1500$ and $2000 \mathrm{mg} \mathrm{L}^{-1}$. The seedlings were arranged in a randomized block design with four replications, each experimental unit consisting of 25 plants, totaling 500 plants in the experimental field. 185 days after planting the following characteristics were evaluated: plant height; root system length; leaf area; stem diameter; dry mass of part area; dry mass of the root system; total dry mass; and Dickson Quality index. The application of IBA promoted growth and quality of seedlings, however the high concentrations limited its development. Thus, we indicated the concentration of $1420.10 \mathrm{mg} \mathrm{L}^{-1}$ because this dosage implied better seedling quality.
\end{abstract}

Keywords: Black pepper; growth regulator; exogenous auxin.

\section{INTRODUÇÃO}

Originária da Índia, a pimenteira-do-reino (Piper nigrum L.) é uma trepadeira perene da família Piperaceae com elevada importância comercial, sendo encontradas em regiões tropicais e subtropicais em diversos lugares no mundo, havendo relatos de seu uso empregado como planta ornamental, na medicina popular, além da utilização como condimento na culinária de inúmeros países (KRISHNAMURTHY et al., 2010).

O Brasil é um dos maiores produtores mundiais da pimenta-do-reino, em 2017, alcançou uma produção de 75 mil toneladas, tendo o Estado do Espirito Santo a maior produtividade média, com $3.566 \mathrm{~kg}$ $\mathrm{ha}^{-1}$, superando a média nacional de 2.742 $\mathrm{kg} \mathrm{ha}^{-1}$ (IBGE, 2018).

O Interesse comercial dessa espécie deve-se aos elevados teores de alcaloides nos frutos, com potencial na indústria farmacêutica para produção de compostos anti-inflamatórios e analgésicos, além de proporcionarem um sabor característico, sendo por isso, quando secos, utilizado como condimento alimentar (GAIA et al., 2007; SECUNDINO, 2012; TASLEEM, et al., 2014).

Em relação a propagação vegetativa ou assexuada, essa é uma técnica agronômica benéfica para cultivo de plantas ou culturas que apresentam dificuldade propagativa, ou com algum impedimento fisiológico, essa técnica é considerada uma maneira rápida e segura de se obter uma nova planta com características idênticas a planta matriz, através da multiplicação de estacas ou fragmentos vegetativos que possuam tecidos com capacidade de reassumir atividades meristemáticas (SILVA, 1984; SECUNDINO, 2012).

Dentre as técnicas de propagação vegetativa, a estaquia está como uma das mais utilizada para Piperaceae, sendo que em algumas espécies o enraizamento pode ser lento, necessitando muitas vezes de reguladores de crescimento que auxiliam e induzem a formação de raízes adventícias, 
melhorando o vigor das mudas (ONNO et al., 1994; ZANETTE, 1995; HARTMAN, 1997).

O ácido-indol-3-butírico (AIB) é um regulador de crescimento, hormônio sintético, muito utilizado na propagação de mudas, trata-se de uma auxina altamente efetiva no estímulo ao enraizamento, devido à sua menor mobilidade, menor fotossensibilidade e maior estabilidade química na planta, acelerando o processo de emergência de primórdios radiculares, aumento no número e qualidade das raízes formadas (MAGEVSKI et al., 2011; LIMA et al., 2018). Entretanto, os resultados são variáveis a depender da espécie ou cultivar utilizada, da concentração e modo de aplicação do AIB, da época do ano, condições ambientais e do tipo da estaca, que mobiliza carboidratos e auxinas endógenas exercendo influência na sobrevivência e emissão de brotações (FACHINELLO et al., 1995; PONTESFILHO et al., 2014).

Na pimenteira-do-reino a influência do AIB na propagação da cultivar Bragantina já foi relatado (AMBROZIM et al., 2017). Entretanto, não se encontrou na literatura estudos de evidenciam o efeito deste regulador de crescimento relacionado a mudas da cultivar Kottanadan. Esta cultivar se destaca por apresentar plantas com porte médio, precocidade e alta produtividade, além de resistência a doenças, características que fazem desta cultivar umas das mais relevantes no Estado do Espírito Santo (SAFRAES, 2016).

Desta forma, objetivou-se por esse estudo avaliar o efeito da aplicação exógena de diferentes concentrações de ácido-indol3-butírico (AIB) no crescimento e na qualidade de mudas de pimenta-do-reino (Piper nigrum L.) cv. Kottanadan.

\section{MATERIAIS E MÉTODOS}

O estudo foi realizado no viveiro de mudas da fazenda Experimental do Instituto Capixaba de Pesquisa, Assistência Técnica e Extensão Rural (INCAPER), localizado no município de Linhares, Norte do Estado do Espírito Santo, Brasil, nas coordenadas geográficas $19^{\circ} 25^{\prime} 03^{\prime \prime}$ de latitude sul e $40^{\circ}$ 04' 50" de longitude oeste. De acordo com a classificação de Köppen, o clima da região e tipo Tropical Aw, com inverno seco e predomínio de chuvas durante o verão (ALVARES et al., 2014). O experimento foi conduzido em casa de vegetação com tela de polipropileno com $50 \%$ de sombreamento durante os dias 11 de setembro de 2018 a 14 de março de 2019.

Para produção das mudas utilizou-se estacas de pimenta-do-reino (Piper nigrum L.) cv. Kottanadan provenientes de ramo ortotrópico, contendo 2 a 3 nós e média de $20 \mathrm{~cm}$ de comprimento obtidas de plantas matrizes com 2,5 anos, bem nutridas e saudáveis. As estacas utilizadas foram de ramos de nó inteiro, eliminando as partes apicais e basais deixando somente a parte mediana e metade das folhas de cada nó, sendo o comprimento do entrenó basal de 2 $\mathrm{cm}$, na extremidade superior do entrenó da estaca procedeu-se o corte em bisel, já na parte basal o corte reto (Figura 1).

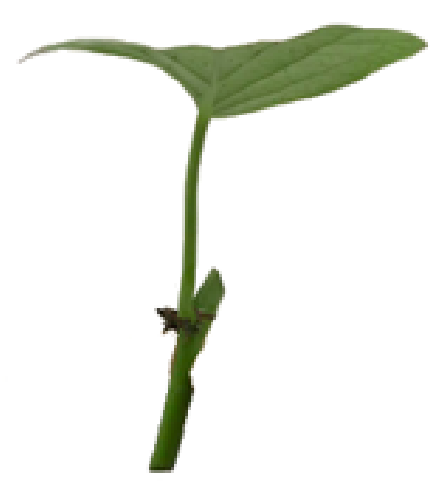

Figura 1. Representação de estacas utilizadas para a produção de mudas de pimenta-do-reino (Piper nigrum L.) cv. Kottanadan.

As estacas foram imersas em solução fungicida de Carbomax ${ }^{\circledR} 500$ SC durante 10 minutos. Posteriormente, foram levadas a laboratório onde tiveram suas bases imersas durante 3 horas em $20 \mathrm{ml}$ na solução do regulado de crescimento ácido- 
indol-3-butírico (AIB) em recipiente plástico com volume $50 \mathrm{ml}$, cada recipiente continha de 10 a 12 estacas. Os tratamentos constituíram na aplicação de diferentes dosagens de AIB via líquido, sendo elas: 0, $500,1000,1500$ e $2000 \mathrm{mg} \mathrm{L}^{-1}$.

Foi plantada uma estaca em cada tubete de polipropileno de $5 \mathrm{~cm}$ de diâmetro superior, $19 \mathrm{~cm}$ de altura e $280 \mathrm{~cm}^{3}$ de volume, contendo substrato comercial Bioplant $^{\circledR}$, acrescidos $3 \mathrm{~g}$ de Osmocote ${ }^{\circledR}$ (5M), com irrigação por micro aspersão automática durante todo $\mathrm{o}$ período experimental. $\mathrm{O}$ delineamento empregado foi em blocos casualizados, com quatro repetições, sendo cada unidade experimental constituída por 25 plantas, totalizando 500 plantas no campo experimental.

Ao final do experimento, 185 dias após o plantio foram avaliadas as características de crescimento: altura de planta (ALT); comprimento do sistema radicular (CSR); área foliar (AF); e diâmetro do caule (DC). Características de biomassa: massa seca da parte área (MSPA); massa seca do sistema radicular (MSSR); e massa seca total (MST). Característica de qualidade de mudas, via estimativa do Índice de Qualidade de Dickson (IQD).

A ALT foi medida da base do colo até a gema apical que deu origem a última folha, com régua graduada, em $\mathrm{cm}$. O CSR foi mensurado com régua graduada, em $\mathrm{cm}$, da base do coleto até ao maior comprimento radicular. A AF foi obtida com o analisador portátil LI-COR, modelo LI-3000C, em $\mathrm{cm}^{2}$. O DC foi obtido por meio de paquímetro digital de precisão, em mm.

A MSPA foi obtida através do corte das mudas próximas ao substrato, para a obtenção da MSSR, as raízes foram cuidadosamente lavadas em água corrente sobre peneira. Posteriormente, para ambas as características os materiais foram acomodados em sacos de papel e secos em estufa de circulação de ar forçada a $65{ }^{\circ} \mathrm{C}$ por período de 72 horas, pesados em balança eletrônica de precisão, em g. A
MST foi obtida a partir da soma da MSPA com a MSSR, tendo sua medida expressa em $g$.

O IQD foi determinado segundo Dickson et al. (1960) pela expressão:

$$
\mathrm{IQD}=\frac{\mathrm{MST}}{\frac{\mathrm{ALT}}{\mathrm{DC}}+\frac{\mathrm{MSPA}}{\mathrm{MSSR}}}
$$

Onde: MST, são os valores da matéria seca total das plantas; ALT é a altura das plantas; DC é o diâmetro de caule das plantas; MSPA é a matéria seca da parte área das plantas; e MSSR é a matéria seca do sistema radicular.

Os dados foram submetidos a análise de variância pelo teste $\mathrm{F}$, a $5 \%$ de probabilidade, quando significativo, ajustou-se modelos de regressão que melhor explicaram o efeito da dosagem de AIB sobre as características analisadas. Os pontos de máxima foram definidos a partir da derivada primária de cada equação. Todas as análises estatística e elaboração de gráficos foram realizadas com o auxílio do software R através do pacote stats (R CORE TEAM, 2019).

\section{RESULTADOS E DISCUSSÃO}

Após a análise de variância observou-se que houve diferença significativa $(\mathrm{p}<0,05)$ para as características altura de planta (ALT), comprimento do sistema radicular (CSR), área foliar (AF), massa seca total (MST) e índice de qualidade de Dickson (IQD), atestando que a concentração de ácidoindol-3-butírico (AIB) aplicada interferiu nestas características das mudas de pimentado-reino (Piper nigrum L.) cv. Kottanadan. Observou-se também que não houve diferença estatística para as características diâmetro de caule (DC), massa seca da parte aérea (MSPA) e massa seca do sistema radicular (MSSR) em relação a concentração de AIB aplicada. 
A resposta das características de crescimento das mudas está representada na Figura 2. A ALT apresentou efeito quadrático com altura máxima de $31,54 \mathrm{~cm}$ na concentração de $1425,60 \mathrm{mg} \mathrm{L}^{-1}$ de AIB e coeficiente de determinação $\left(R^{2}\right)$ de 0,9816 (Figura 2A). O CSR teve ajuste quadrático com maior comprimento de
$29,11 \mathrm{~cm}$ na concentração de $1270,94 \mathrm{mg} \mathrm{L}$ ${ }^{1}$ de AIB e $\mathrm{R}^{2}$ de 0,9789 (Figura 2B). Para AF o ajuste observado foi o quadrático com maior área de $423,33 \mathrm{~cm}^{2}$ na concentração de $1680,32 \mathrm{mg} \mathrm{L}^{-1}$ de AIB e $\mathrm{R}^{2}$ de 0,9829 (Figura 2C). Em relação ao DC não foi observado diferença com valor médio de $5,88 \mathrm{~mm}$ para todos os tratamentos.

A

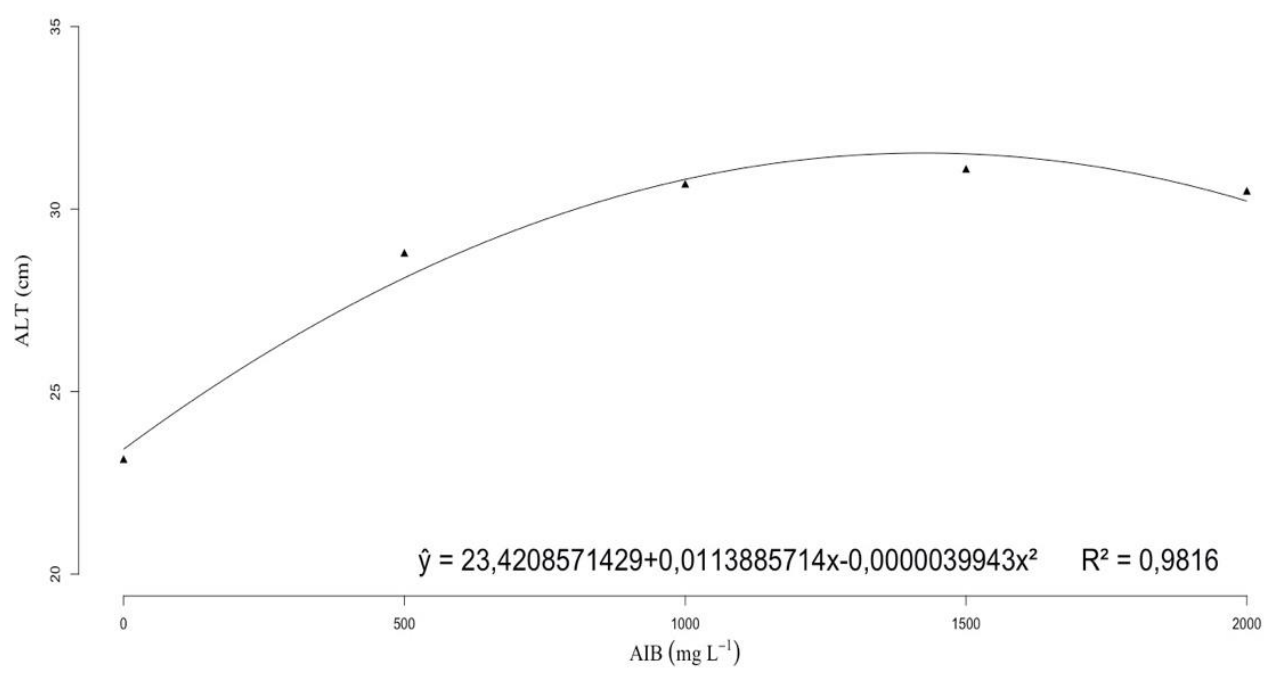

B

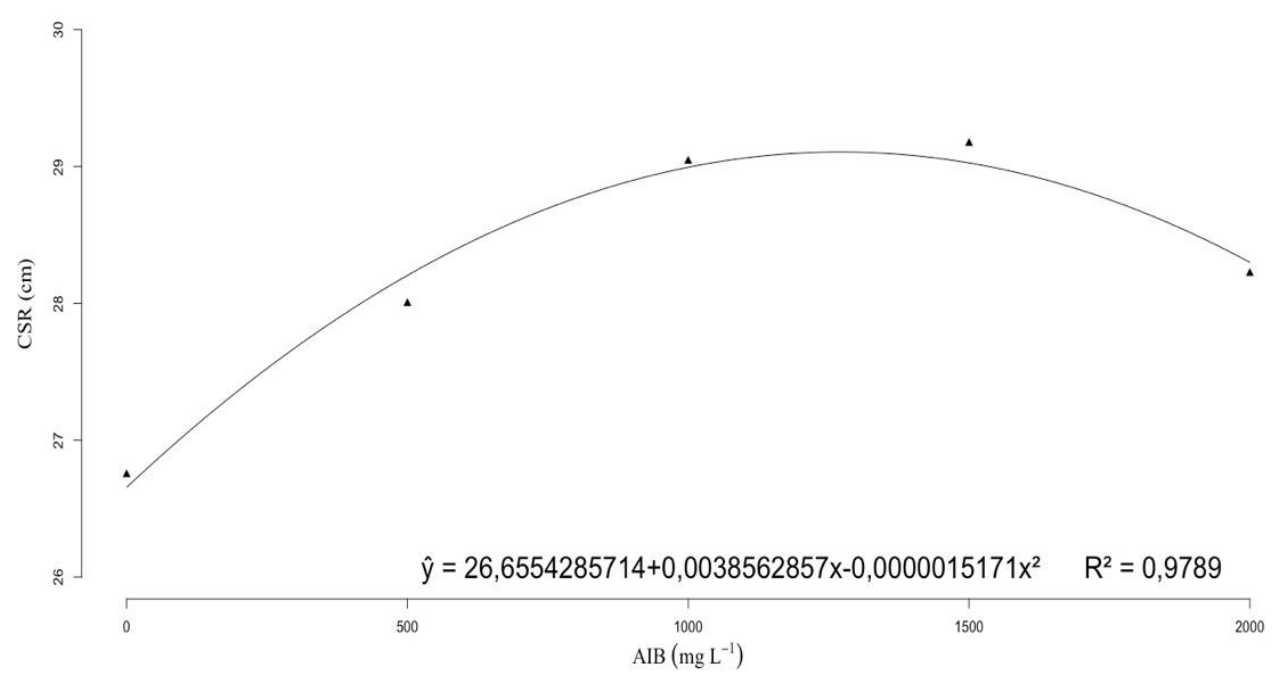




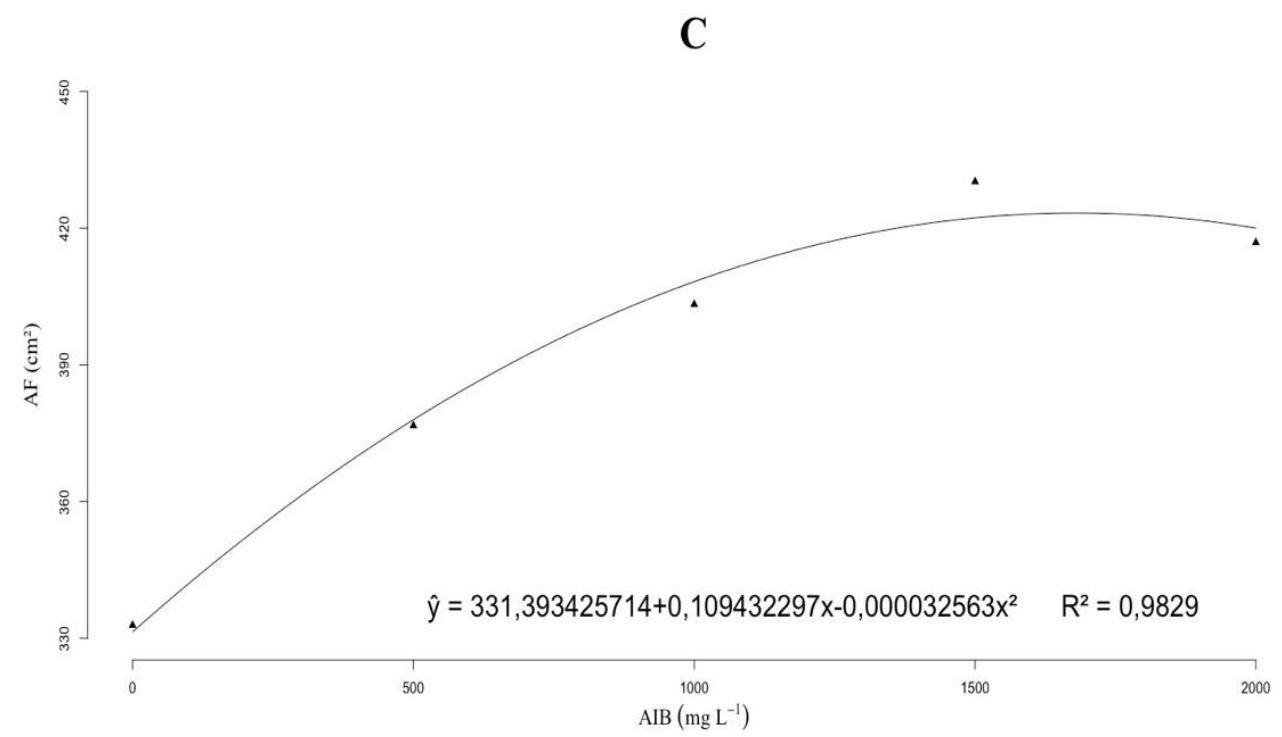

Figura 2. Efeito de diferentes concentrações de ácido-indol-3-butírico (AIB) na Altura de planta (ALT) (A), comprimento do sistema radicular (CSR) (C) e área foliar (AF) (C) de mudas de pimenta-do-reino (Piper nigrum L.) cv. Kottanadan.

É notório, que em concentrações muito baixas ou muito altas de AIB há interferência negativa nas características de crescimento das mudas de Piper nigrum L. cv. Kottanadan, isso ocorre pois em baixas dosagens de regulador de crescimento, a indução de raízes por exemplo é mais lenta e menos uniformes (GALLE, 1995). Já em altas dosagens, a aplicação excessiva de AIB pode levar a fitotoxidez impedindo que o material propagativo não tenha seu máximo desenvolvimento (PIO, 2003). Segundo Taiz e Zeiger (2013), o tempo e a concentração em que o material vegetativo é exposto à auxina exógena inibe ou estimula o crescimento e a diferenciação dos tecidos, sendo que há um nível ideal para que estas respostas aconteçam. Assim, é primordial que se utilize de forma correta a dosagem ideal de reguladores de crescimento para cada espécie que se deseje trabalhar, sendo que essa concentração é variável para cada espécie (HARTAMANN et al., 2002).

A aplicação de AIB tem efeito na indução radicular uma vez que esse regulador de crescimento tem atuação relacionada a aceleração da rizogênese nas mudas, favorecendo o aparecimento das raízes, o que não acorre na ausência desse composto (PIZZATTO et al., 2011). Segundo Hartmann et al. (2011) quando se faz uso de reguladores de crescimento, o desenvolvimento do sistema radicular é positivo, entretanto, existe um ponto máximo de onde a partir do qual a indução é inibida. De fato, corroborando com estas afirmações, é possível constatar no presente estudo que com a concentração de $0 \mathrm{mg} \mathrm{L}^{-1}$ o CSR ficou limitado, ao passo que houve crescimento gradual até a concentração de $1270,94 \mathrm{mg} \mathrm{L}^{-1}$ de onde houve decréscimo dos valores para esta característica.

$\mathrm{O}$ uso exagerado de reguladores de crescimento pode acarretar em intensa proliferação de células inibindo $o$ crescimento radicular e conseguintemente limitando o desenvolvimento da parte área das mudas (SILVA et al., 2004). Além disso, as raízes desempenham papel fundamental na absorção dos nutrientes e água presentes no substrato, desta forma, raízes em maior número e comprimento permitem melhor desenvolvimento das mudas (AMARAL et al., 2017; AMBROZIM et al., 2017). Em contrapartida, as folhas através do processo da fotossíntese, produzem carboidratos necessários para a manutenção e 
crescimento tanto do sistema radícula, quanto da parte área das plantas. Supõe-se, por isso, que as mudas de Piper nigrum L. cv. Kottanadan tiveram ajuste semelhante para o CSR, ALT e AF já que é sabido, que estas características interagem entre si para o pleno desenvolvimento vegetativo das plantas.

Em relação as características de biomassa, para a MSPA e MSSR, não foram encontradas diferenças estatísticas entre os tratamentos com médias de 5,26 e 0,64 g, respectivamente. Entretanto, para a MST observou-se que o ajuste quadrático foi o mais adequado com o máximo acumulo de $6,27 \mathrm{~g}$ na concentração de $1253,40 \mathrm{mg} \mathrm{L}^{-1}$ de AIB e $\mathrm{R}^{2}$ de 0,8828 (Figura 3).
Vale ressaltar, que o acúmulo de MST pela planta esta intimamente ligado as características de crescimento como por exemplo o CSR, ALT e AF evidenciado neste estudo pelo ajuste destas características. Isso acontece, segundo Melo et al. (2007) pelo fato das plantas que apresentam maior área foliar possuírem maior capacidade de fazer interceptação luminosa para a pratica da fotossíntese resultando no melhor desenvolvimento como já visto anteriormente neste estudo o que consequentemente irá influenciar de forma positiva no acúmulo de massa seca pela planta.

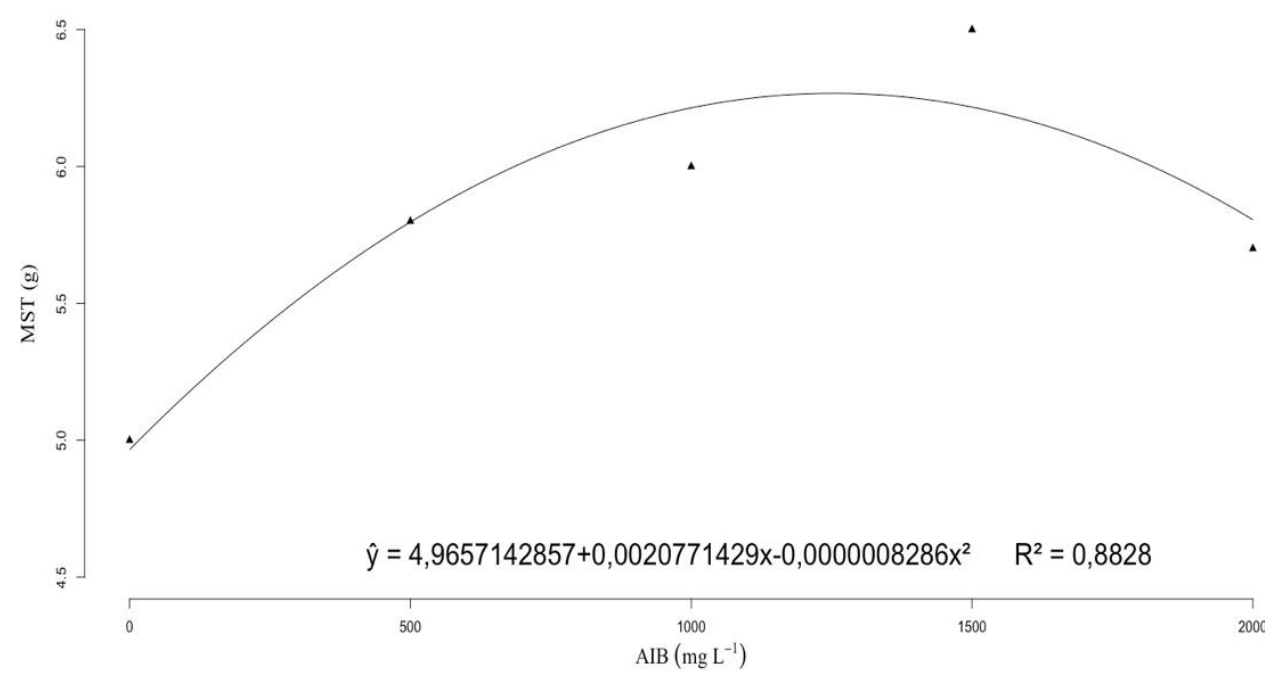

Figura 3. Efeito de diferentes concentrações de ácido-indol-3-butírico (AIB) na massa seca total de mudas de pimenta-do-reino (Piper nigrum L.) cv. Kottanadan

A qualidade das mudas, representada pelo IQD apresentou ajuste quadrático com maior índice de 0,476 na concentração $1420,10 \mathrm{mg} \mathrm{L}^{-1}$ de AIB e $\mathrm{R}^{2}$ de 0,9286, atestando que mais de $92 \%$ do IQD foi influenciado pela dosagem de AIB aplicada (Figura 4).

O IQD leva em consideração em sua formula característica de crescimento como a altura e o diâmetro de caule e as características de biomassa seca, sendo desta forma bem representativa em relação a qualidade das mudas (SILVA et al., 2013). Além disso, segundo Binotto et al. (2010), este índice é capaz de identificar com maior aptidão para a sobrevivência quando transplantadas para o campo, já que elas tendem a se adaptarem melhor as condições permitindo maior desenvolvimento, assim as mudas que apresentam maiores valores para esse índice possuem maior vigor e robustez. 


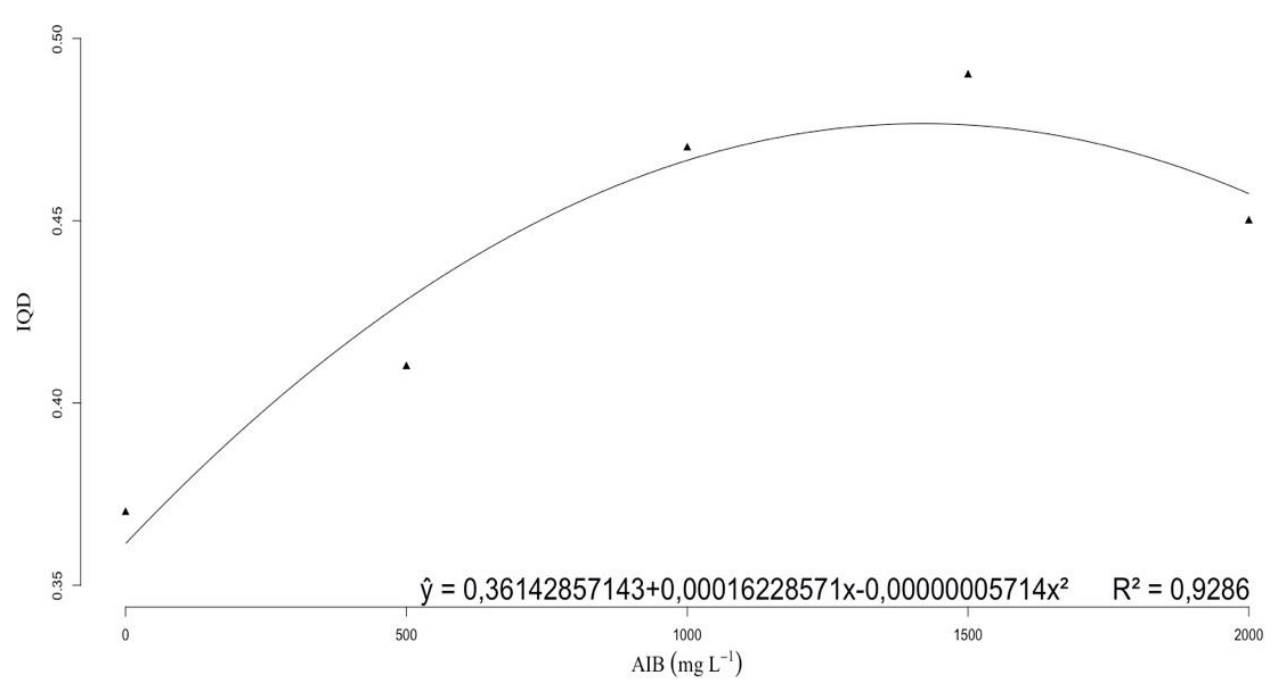

Figura 4. Efeito de diferentes concentrações de ácido-indol-3-butírico (AIB) no índice de qualidade de Dickson (IQD) de mudas de pimenta-do-reino (Piper nigrum L.) cv. Kottanadan.

Os resultados aqui apresentados, demostram que houve influência do regulador de crescimento ácido-indol-3butírico (AIB) no crescimento e na qualidade de mudas de Piper nigrum L. cv. Kottanadan, sendo que as menores e as maiores concentrações estabelecidas neste estudo tiveram efeito negativo nas mudas, havendo assim um ponto de máxima ideal para melhora nos valores de cada característica analisada.

\section{CONCLUSÕES}

A aplicação exógena de auxina através do regulador de crescimento ácidoindol-3-butírico (AIB) na base das estacas promoveu melhoras no crescimento e na qualidade de mudas de pimenta-do-reino (Piper nigrum L.) cv. Kottanadan, porém sobre concentrações elevadas há limitações em seu desenvolvimento, assim, recomenda-se a concentração de 1420,10 $\mathrm{mg} \mathrm{L}^{-1}$, pois sob essa dosagem as mudas tiveram melhor índice de qualidade de Dickson (IQD) característica essa que define qualidade de mudas.
Em resumo, as dosagens de AIB entre 1253,40 e $1680,32 \mathrm{mg} \mathrm{L}^{-1}$ aplicadas na base das estacas de Piper nigrum L. cv. Kottanadan foram as mais indicadas para todas as características avaliadas. Entretanto, estima-se que a dosagem de $1420,10 \mathrm{mg} \mathrm{L}^{-1}$ de AIB proporcione maior qualidade das mudas, garantindo pelos maiores valores do IQD.

\section{REFERÊNCIAS}

ALVARES, C. A.; STAPE, J. L.; SENTELHAS, P. C.; GONÇALVES, J. L. M.; SPAROVEK, G. Köppen's climate classification map for Brazil. Meteorologische Zeitschrift, v.22, n.6, p.711-728. 2014.

AMBROZIM, C. S.; FURTADO, J. G.; VALANI, R. S.; POSSE, R. P.; VARNIER, E.; POSSE, S. C. P.; ARANTES, S. D.; ARANTES, L. O.; OLIVEIRA, E. C. Propagação de pimenta do reino em diferentes concentrações de ácido indolbutírico. Revista Ifes Ciência, v. 3, n.2, p.17-28. 2017.

AMARAL, W.; BIASI, L. A.; MACHADO, M. P.; DESCHAMPS, C. Ácido 
indolbutírico no enraizamento de estacas de louro (Laurusnobilis L.). Revista Acadêmica: Ciência Animal, v. 11, p.5963, 2017.

BINOTTO, A. F.; LÚCIO, A. D.; LOPES, S. J. Correlations between growth variables and the Dickson quality index in forest seedlings. Revista Cerne, Lavras, v.16, n.4, p.457-464. 2010.

DICKSON, A.; LEAF, A. L.; HOSNER, J. F. Quality appraisal of white spruce and white pine seedling stock in nurseries. Forest Chronicles, v. 36, p. 10-13, 1960.

FACHINELLO, J. C.; HOFFMANN, A.; NACHTIGAL， J. C.; KERSTEN， E.; FORTES, G. R. L. Propagação de plantas frutíferas de clima temperado. Pelotas: UFPel, 1995.

GAIA, J.M.D.; MOTA, M.G.C.; DERBYSHIRE， M.T.V.C.; OLIVEIRA, V.R.; COSTA, M.R.; MARTINS, C. S.; POLTRONIERI, M.C. Caracterização de acessos de pimenta-do-reino com base em sistemas enzimáticos. Horticultura Brasileira. v.25, n.3, p.333-342. 2007.

GALlE, F. C. Azaleas. Portland: Timber, 1995.

HARTMANN, H. T.; KESTER, D. E.; DAVIES, F. T.; GENEVE, R. L. The biology of grafting. In: Hartmann, H. T.; Kester, D. E.; Davies, F. T.; Geneve, R. L. (Org.). Plant Propagation: Principles and Practices. New Jersey: Prentice Hall, 1997, $770 \mathrm{p}$.

HARTMANN, H. T.; KESTER, D. E.; DAVIES JUNIOR, F. T.; GENEVE, R. L. Plant propagation: principles and practices. 7. ed. New Jersey: Prentice Hall, 2002. 880 p.

HARTMANN, H. T., KESTER, D. E., DAVIS JÚNIOR., F. T.; GENEVE, R. L. Plant propagation: principles e practices. 8 . ed. Boston: Prentice Hall, 2011, 919 p.

IBGE - Instituto Brasileiro de Geografia e Estatística. Levantamento Sistemático da Produção Agrícola, Safra 2017. Disponível em: https://sidra.ibge.gov.br/tabela/1618 Acesso em: 02/12/2018.

KRISHNAMURTHY, K. $\quad$ S.; PARTHASARATHY, V. A.; SAJI, K. V.; KRISHNAMOORTHY, B. Ideotype concept in black pepper (Piper nigrum L.). Journal of Spices and Aromatic Crops, v. 19, n. 1\&2, p.1-13, 2010.

LIMA, C. C; OHASHI, T. S; SILVEIRA, A. S. Efeito de diferentes concentrações de AIB e procedências geográficas no enraizamento de estacas de Paricá. Ciência Florestal, v. 28, n. 3, p.1282-1292, 2018.

MAGEVSKI, G. C; CZEPAK, M. P; SCHMILDT E. R.; ALEXANDRE R. S.; FERNANDES A. A. Vegetative propagation of wild species of the genus Piper, with potential for use as rootstocks in black pepper (Piper nigrum). Revista Brasileira Plantas Medicinais. v.13, p.559-563. 2011.

MELO, A. S.; COSTA, C. X.; BRITO, M. E. B.; VIÉGAS, P. R. A.; SILVA JÚNIOR, C. D. Produção de mudas de mamoeiro em diferentes substratos e doses de fósforo. Revista Brasileira de Ciências Agrárias. v. 2, n. 4, p. 257-261, 2007.

ONNO, E.O.A.; RODRIGES, J.D.; PINHO, S.Z. Ação de auxinas e/ou boro, no processo de formação de raízes em estacas de café (Coffea arabica L. cv. Mundo Novo). Arquivos de Biologia e Tecnologia. v.37, n.1, p.157-66, 1994.

PIO, R. Ácido indolbutírico e sacarose no enraizamento de estacas apicais e desenvolvimento inicial da figueira (Ficus carica L.). 2002. 109 f. Dissertação (Mestrado em Agronomia) - Universidade Federal de Lavras, Lavras, 2002.

PIZZATTO, M.; WAGNER JÚNIOR, A.; LUCKMANN, D.; PIROLA, K.; CASSOL, D. A.; MAZARO, S. M. Influência do uso de AIB, época de coleta e tamanho de estaca na propagação vegetativa de hibisco por estaquia. Revista Ceres, v. 58, n.4, p. 487492, 2011 
PONTES FILHO, F. S. T.; ALMEIDA, E. I. B.; BARROSO, M. M. A.; CAJAZEIRA, J. P.; CORRÊA, M. C. M. Comprimento de estacas e concentrações de ácido indolbutírico (AIB) na propagação vegetativa de pitaia. Revista Ciência Agronômica, v. 45, n. 4, p. 788-793, 2014.

$\mathrm{R}$ CORE TEAM. R: a language and environment for statistical computing. Vienna: $\mathrm{R}$ Foundation for Statistical Computing, 2019.

SAFRAES. Cultivos que valem ouro. Redação Safra ES, 15 de abril de 2016. Disponível em: $<$ https://www.safraes.com.br/geral/cultivosque-valem-ouro-1>. Acesso em: 07 de mar. De 2020

SECUNDINO, W. Propagação vegetativa da pimenteira-do-reino: avaliação de cultivares, níveis de AIB e substratos. 2012. 71 f. Dissertação (Agricultura Tropical). Universidade Federal do Espírito Santo, São Mateus, 2012. 